\title{
Genetic aspects of communication during male-male competition in the Madagascar hissing cockroach: honest signalling of size
}

\author{
DEBORAH C. CLARK* \& ALLEN J. MOORE \\ Department of Entomology, Center for Ecology, Evolution and Behavior, University of Kentucky, S225 Agricultural \\ Science North, Lexington, KY 40546-0091, U.S.A.
}

\begin{abstract}
Male Madagascar hissing cockroaches, Gromphadorhina portentosa, engage in agonistic contests with other males and produce audible sounds or 'hisses' during these interactions. Hisses are used to maintain, rather than to establish, social relationships among males. The agonistic hisses of males are variable and could be used as signals to communicate size or competitive ability of an individual. In this study we examined how size influences male-male competition, as well as the genetic variation and covariation of male body size and components of the agonistic hiss. We found that male size affected the outcome of agonistic interactions between pairs of males: a male that dominated in a pair was significantly larger than the male that was subordinate. However, we found no differences in the hisses produced by dominant and subordinate males after controlling for male weight. We estimated heritabilities, evolvability and genetic correlations for male size and characteristics of the hiss from a full-sib analysis of brothers. The patterns of heritabilities and evolvabilities were very similar. The heritabilities of both male weight and duration of the hiss were significantly greater than zero. There was a significant positive genetic correlation between duration of the agonistic hiss and male weight, and a significant negative genetic correlation between hiss duration and the beginning dominant frequency. There was also a positive phenotypic correlation and a negative environmental correlation between male weight and hiss duration. Thus, hiss duration can signal the present influence of the environment on male size, whereas information from hiss duration and beginning dominant frequency can signal the male's ability to transmit genetic influence for size. Our results are discussed in terms of honest signalling and assessment during male-male and courtship interactions.
\end{abstract}

Keywords: agonism, evolvability, genetic correlations, heritability, honest signalling, sexual selection.

\section{Introduction}

Conflicts between males over limited resources such as mates can be costly and may result in serious injury to the individuals involved. Males are expected to engage in escalated encounters only when their fighting ability is greater than their opponent's or when the opponent's fighting ability is unclear (Parker, 1974). However, to avoid costly fights, males must be able to assess their competitive ability relative to that of their opponent and adjust their behaviour accordingly (Huntingford \& Turner, 1987).

In competitive situations, males should only respond to reliable, honest advertisements of fighting ability

*Correspondence: Department of Biology, Middle Tennessee State University, Davis Science Building, Murfreesboro, TN 37132, U.S.A.
(Guilford \& Dawkins, 1991). Both senders and receivers will benefit from honest signalling if unnecessary interactions are avoided as a result (Parker, 1974; Maynard Smith, 1982). Male size is often used to assess the competitive ability of an opponent because size typically correlates with fighting ability and morphological traits are difficult to cheat (Dawkins \& Krebs, 1978). For example, in some insects (Eberhard, 1979; Thornhill, 1983; Hoffman, 1988; Boake, 1989), arachnids (Potter et al., 1976; Faber \& Baylis, 1993) and anurans (Davies \& Halliday, 1978; Robertson, 1986) larger males win aggressive interactions more frequently than smaller males. Other signals that are correlated with male size, such as acoustic cues, can therefore function as honest signals. Because of their correlation with male size, these cues also should be difficult to mimic and are expected to be costly to 
produce (Dawkins \& Krebs, 1978). For example, males can assess the weight of the opponent using features of the male sound in the anurans Uperoleia rugosa (Robertson, 1986), Bufo bufo (Davies \& Halliday, 1978) and Acris crepitans blanchardi (Wagner, 1989).

Most studies documenting the relationship between male signals and male size have examined phenotypic variation only. However, the evolution of a character depends on a genetic component to that variation as well as selection (Darwin, 1859; Fisher, 1958). Although the role of inheritance in the evolution of behaviour has been receiving increasing attention (Boake, 1989), genetic investigations of sexually selected behaviour and communication are limited (Boake, 1991).

Recent studies addressing the evolution of male traits have focused mainly on female choice. Several studies have demonstrated that acoustic signals produced by males during courtship are influenced by the genetic differences among individuals. Significant heritabilities were found for song characteristics that influence female mate choice in Gryllus integer (Hedrick, 1988), G. firmus (Webb \& Roff, 1992), Ribautodelphax imitans (De Winter, 1992), and Drosophila montana (Aspi \& Hoikkala, 1993). Male size also provides a basis for female discrimination and is heritable in a variety of animal species (Mousseau \& Roff, 1987; Roff \& Mousseau, 1987).

Studies examining the genetic basis of male-male competition are more limited and have focused mainly on social behaviour and not communication. Hoffman (1988) and Riechert \& Maynard Smith (1989) examined the inheritance of behaviour associated with territoriality. Dewsbury (1990) and Moore (1990) examined the inheritance of social dominance abilities in mice and cockroaches, respectively. Studies examining the genetic basis of both behaviour and communication used during male-male competition are necessary to complete our understanding of the evolution of social signals.

Our goal in this study was to investigate factors influencing male-male interactions in the cockroach, Gromphadorhina portentosa. Males in this species form dominance associations that determine priority of access to females (Leibensperger et al., 1985). Interactions among males involve overt aggression (Barth, 1968; Nelson \& Fraser, 1980; Breed et al., 1981; Clark \& Moore, 1994), aggressive displays (Clark \& Moore, 1994 ) and the production of sound ('agonistic hisses'; Nelson \& Fraser, 1980; Clark \& Moore, 1995b). In $G$. portentosa, aggressiveness and characteristics of the agonistic hiss are influenced by male weight: larger males are more aggressive (Clark \& Moore, 1994) and have longer, lower frequency hisses than smaller males
(Clark \& Moore, 1995b). Hissing also appears to be an important, but not necessary, component of male agonistic interactions (Clark \& Moore, 1995b). Hissing maintains established, stable associations among males and varies with the social status of the individual: dominant males hiss more than subordinate individuals (Clark \& Moore, 1995b). While the amount of hissing may influence the escalation of male-male interactions, it is also possible that characteristics of the hiss are used to assess opponents (Clark \& Moore, 1995a,b; Clark et al., 1995). Male G. portentosa also hiss during courtship interactions with females. The courtship hisses of individuals do not differ from the agonistic hisses examined in this study (Clark \& Moore, 1995a). Therefore, although the focus of this study is intrasexual competition, we should also gain insight into the potential for female mate choice based on male hisses.

In this study we examined the genetic basis of variation in male body size and components of the agonistic hisses produced by males during male-male competition. First, we examined the consequences of size and signal differences for individuals during male-male competition by comparing the size and attributes of the agonistic hisses of dominant and subordinate males. We predicted that if size were important the winners of paired encounters would be larger than their opponents. If agonistic hisses convey information about male status independent of male size, we expected the hisses of dominant and subordinate males to differ in acoustic characteristics after controlling for the effects of male weight. Secondly, we determined the full-sib heritability of male size as well as the rate, dominant frequency and duration of agonistic hisses. In a previous study, we found that the rate, dominant frequency and duration of the agonistic hisses of individuals have significant repeatabilities (Clark \& Moore, 1995b). Finally, we examined the genetic and phenotypic correlations among characteristics of the agonistic hiss and between characteristics of the hiss and male weight. We expected significant genetic correlations among components of the hiss and male weight if agonistic hisses function as honest signals of male weight and, therefore, fighting ability.

\section{Materials and methods}

\section{Insect rearing}

G. portentosa male and female nymphs were reared as family groups in containers $(27 \times 20 \times 10 \mathrm{~cm})$ containing food, water, a paper tube shelter and wood shaving bedding. Fresh food and water were provided weekly and in excess. All individuals were maintained in an environmentally controlled room at 12:12 (L:D) 
photoperiod at $26-28^{\circ} \mathrm{C}$ and ambient humidity. Our experimental population of males was obtained from 56 families from separate, noninbred genealogies. Family groups were obtained by isolating mated females from mass colonies until the birth of the first clutch. These mass colonies contained several thousand individuals. We reared nymphs together because they do not display aggressive behaviour.

Prior to adult emergence, males from each family were isolated in individual cages $(11 \times 11 \times 3 \mathrm{~cm})$. Males were isolated as older nymphs ( 5 months after birth) to prevent individuals from learning about their competitive ability through adult experiences of winning and losing. Males remained isolated until they were used in experiments at 8-10 months after birth. Under the rearing conditions for our colony, sexual maturity is reached at 6-7 months after birth so all individuals used in our experiments were fully adult. Individual males used in this study were marked with a paper number glued to the pronotum to allow the observer to identify individuals.

\section{Establishment and observation of pairs}

We established 106 pairs of males by randomly placing two unrelated males together in an arena $(27 \times 20 \times 10$ $\mathrm{cm}$ ) containing food, water, one wood platform and wood shaving bedding. This arena was then placed in a sound-controlled chamber (below) for videotaping. Each pair was unique (different families) providing an independent data set. All pairs were allowed to establish social associations over a 10-day period, a length of time sufficient for stable associations to form (Clark \& Moore, 1994). Males were then observed for $30 \mathrm{~min}$ in a neutral arena $(27 \times 20 \times 10 \mathrm{~cm})$ containing wood shaving bedding and one wood platform in a sound-controlled chamber (see below). All observations were conducted during the scotophase under a dim red light and videotaped with a Sony CCD camera (Model SSC-M370) fitted with a Tamron wide-angle lens on a Sony Hi8 video recorder (Model EVO-9500) to allow detailed analysis. Hissing by individual males also was recorded at this time (see below). The behaviour initiated by each male was scored and used to determine the winner and loser of the interaction. Winning/losing was defined on the basis of behaviour that involved direct contact with the opponent (Abdomen Flick, Abdomen Push, Butt, Lunge) or noncontact behaviour (Approach) that elicited subordinate responses (Crouch, Retreat). As in previous studies (Clark \& Moore, 1994, 1995a,b; Clark et al., 1995), we classified males that displayed at least 70 per cent more aggressive behaviour than their opponent and displayed at least three aggressive acts per observation period as dominant males. The opponents of these males were classified as subordinate. If a dominant and subordinate male could not be determined for the interaction, the encounter was scored as a draw and the males were not ranked.

\section{Sound recording and analysis}

We recorded the hisses of males during 100 paired interactions. All hisses that occurred were recorded in a $1.1 \times 0.7 \times 0.9 \mathrm{~m}$ sound-controlled chamber. This chamber was a chest freezer lined with $0.64 \mathrm{~cm}$ eggcarton foam on the inside and covered with a vinyl barrier and $0.64 \mathrm{~cm}$ acoustical foam (Illbruck ProSpec composite) on the outside. For each individual, we recorded multiple agonistic hisses (2-4 hisses) using a Brüel and Kjaer $1.27 \mathrm{~cm}$ prepolarized condenser microphone (Model 4176) fitted to a Brüel and Kjaer sound level meter (Model 2235). Sounds were outputted to a Shure audio mixer (Model M267) and recorded on the Sony Hi8 video recorder. The microphone was held in a fixed position $3 \mathrm{~cm}$ above the centre of the arena. Recordings were made continuously during the observation periods described above.

Of the 200 males we observed, only 118 hissed during the observation period. From recordings of each individual we measured the duration (s), dominant frequency $(\mathrm{kHz}$; the frequency peak with the highest amplitude) of the beginning and end of the hiss, as well as hiss rate (number per min). These attributes of the hiss have been shown in a previous study to be related to male weight, have high repeatabilities and may function as indicators of size or male rank (Clark \& Moore, $1995 \mathrm{~b}$ ). Not all recordings yielded data on all attributes (see below).

All recordings were sampled with the SoundScope software package (GW Instruments) at 44100 samples/s using a Macintosh Quadra 950 computer equipped with a 16-bit Audiomedia II A/D soundboard. The frequency resolution of our measurements was approximately $11 \mathrm{~Hz}$. All hisses were analysed with the SoundScope software package. The dominant frequency of agonistic hisses was quantified from a power spectrum and duration was quantified from the oscillogram. Because some hisses are frequency modulated (Clark \& Moore, 1995a,b), dominant frequency was measured at the beginning and end of the hiss. The beginning and end measurements (single windows of $30 \mathrm{~ms}$ ) were made within the first and last $0.1 \mathrm{~s}$ of the hiss, respectively. The SoundScope program provides a numerical output containing frequency peaks and their corresponding amplitude for the time specified. If two or more frequency peaks corresponded to the highest amplitude, we were not able to determine the dominant 
frequency for that measurement. In addition to dominant frequency and duration, we also examined the number of hisses produced by an individual during the observation period (hiss rate). We did not include data on amplitude because of uncontrolled variation in the male's distance from the microphone as well as the orientation of the individual while hissing. For each individual, average values for each characteristic were analysed.

\section{Male weight, agonistic hisses and the outcome of interactions}

Our first objective was to determine if the outcome of male-male interactions was influenced by the size of the opponents. Prior to placing males in pairs, individuals were weighed to within $0.001 \mathrm{~g}$ using a Mettler balance (Model AE 100) on 3 consecutive days. We then used an average weight for each male in all analyses. We compared the size of dominant and subordinate males for each interaction with paired comparison $t$-tests with significance levels determined by randomization (Manly, 1991). All levels of significance were determined by 1000 randomizations.

In a second test, we examined how variation in male agonistic hisses related to the outcome of male-male interactions by comparing the hisses of dominant and subordinate males. We compared the dominant frequencies and durations of the agonistic hisses of dominant and subordinate males in each interaction with a repeated measures analysis of covariance. Male weight was used as a cofactor in this analysis because male weight influences both the duration and dominant frequency of agonistic hisses (Clark \& Moore, 1995b). Levels of significance were determined with sequential Bonferroni-corrected probabilities (Rice, 1989).

\section{Genetic basis of male weight and agonistic hisses}

Data were collected from full-sib brothers from 56 families (2-4 brothers per family) for male weight and hiss rate. For the duration and dominant frequency measurements of agonistic hisses, we collected data from 43 families. We estimated the heritabilities based on ANOVA of full-sib data with the following model:

$$
Y_{i k}=\mu+\alpha_{i}+e_{i k} \text {, }
$$

where $\mu$ is the common mean, $\alpha_{i}$ is the effect of the $i$ th mating, and $e_{i k}$ is the uncontrolled environmental and genetic deviations attributable to the $i$ th male with a single dam and sire (Becker, 1984). Variance components were estimated from ANOVA using the SYSTAT statistical package (Wilkinson, 1990). The experimental design was unbalanced so we corrected for the unequal numbers per subclass following Becker's (1984) formula

$$
n_{0}=\left(\frac{1}{S-1}\right)\left(n_{t}-\left(\Sigma \frac{n_{i}^{2}}{n_{i}}\right)\right) \text {, }
$$

where $n_{0}$ is the corrected number of offspring per family used in calculating expected mean squares, $S$ is the number of matings, $n_{t}$ is the total number of offspring and $n_{i}$ is the number of offspring in family $i$. Full-sib heritabilities were calculated as:

$h^{2}=\frac{2 V_{\mathrm{S}}}{V_{\mathrm{P}}}$,

where $V_{\mathrm{S}}$, the variance among families, estimates half of the additive genetic variance and one-quarter of the dominance variance. $V_{\mathrm{P}}$ is the phenotypic variance. Full-sib estimates of additive genetic variance are expected to be biased by half of the dominance variance plus the full maternal variance (Falconer, 1989). Therefore, full-sib estimates of heritability are also expected to be biased upward (Becker, 1984). Standard errors of heritabilities were calculated using the formulas provided by Becker (1984) correcting for unbalanced numbers of offspring per family:

$\mathrm{SE}\left(h^{2}\right)=2 \sqrt{\frac{2\left(n_{t}-1\right)(1-t)^{2}\left[1+\left(n_{0}-1\right) t\right]^{2}}{n_{0}^{2}\left(n_{t}-S\right)(S-1)}}$,

where $t$ is the intraclass correlation and all other variables are as above. Heritabilities were determined to be significantly different from zero if the coefficient exceeded twice the standard error.

Houle (1992) has suggested that a measure of evolvability is preferable to heritability to assess levels of genetic variation for a character. Evolvability is assessed by comparing coefficients of additive genetic variation $\left(C V_{\mathrm{A}}\right) . C V_{\mathrm{A}}$ is calculated as:

$100 \frac{\sqrt{V_{\mathrm{A}}}}{\bar{X}}$

where $V_{\mathrm{A}}$ is the additive genetic variation for a character and $\bar{X}$ is the mean. We calculated $C V_{\mathrm{A}}$ for all of our characteristics using a full-sib estimate of $V_{\mathrm{G}}$ (see above) which is likely to overestimate $V_{\mathrm{A}}$.

Genetic relationships among characters as well as the heritability of single characters can influence the evolution of phenotypes (Lande, 1979, 1980, 1982). We calculated phenotypic $\left(r_{\mathrm{P}}\right)$, genetic $\left(r_{\mathrm{G}}\right)$ and environmental $\left(r_{\mathrm{E}}\right)$ correlations between male weight, hiss rate, hiss duration and our measures of dominant frequency. Phenotypic correlations were calculated 
with a Pearson correlation matrix and significance was determined with sequential Bonferroni-corrected probabilities (Rice, 1989). Genetic correlations were estimated following Becker (1984) as:

\section{$\frac{\operatorname{Cov}_{\mathrm{s}}}{\sqrt{V_{\mathrm{S}(\mathrm{X})} V_{\mathrm{S}(\mathrm{Y})}}}$}

where $\operatorname{Cov}_{\mathrm{S}}$ is the between-family component of covariance for traits $\mathrm{X}$ and $\mathrm{Y}, V_{\mathrm{S}(\mathrm{X})}$ and $V_{\mathrm{S}(\mathrm{Y})}$ are the between-family variance components for traits $\mathrm{X}$ and $\mathrm{Y}$, respectively. Covariances were estimated from sums of cross product estimates from MANOVA using the SYSTAT statistical package (Wilkinson, 1990). Genetic correlations were calculated using the number of individuals corrected for unequal family size $\left(n_{0}\right)$. Standard errors were calculated according to the method of Falconer (1989). Genetic correlations were determined to be significantly different from zero if the correlation coefficient exceeded twice the standard error. Environmental correlations were calculated using the equation:

$$
r_{\mathrm{E}}=\frac{r_{\mathrm{P}}-h_{\mathrm{X}} h_{\mathrm{Y}}}{e_{\mathrm{X}} e_{\mathrm{Y}}},
$$

where $h$ is the square root of heritability and $e=\sqrt{\left(1-h^{2}\right)}$ (Falconer, 1989).

\section{Results}

\section{Male weight, agonistic hissing and the outcome of interactions}

Dominant males were significantly larger than their subordinate opponents $\left(t_{55}=3.700, P=0.005\right)$. On average, dominant males weighed $7.329 \pm 0.320$ (SD) $g$ whereas subordinate males weighed $6.574 \pm 0.019$ (SD) g. Dominant males also hissed more than their subordinate opponents $\left(t_{55}=5.704, P<0.001\right)$. However, status differences were not reflected in hiss characteristics. With weight as a covariate, hisses of dominant and subordinate males did not differ in duration $\left(F_{1,18}=0.489, \quad P=0.494\right)$ nor were the dominant frequencies of the hisses of dominant and subordinate males significantly different (beginning: $F_{1,18}=0.090, P=0.767$; end: $\left.F_{1,17}=0.826, P=0.376\right)$.

\section{Heritability and evolvability of male characteristics}

We estimated the heritability of male weight and characteristics of the agonistic hiss and determined if these estimates were significantly different from zero. Our heritability estimate $\left(h^{2}\right)$ for male weight was high
(Table 1) and significantly greater than zero. Our heritability estimates for the characteristics of male agonistic hisses were lower (Table 1) and only the estimate for duration was significantly greater than zero. Our heritability estimates for the beginning and end dominant frequencies were no greater than their standard errors. The heritability estimate for hiss rate was negative $(-0.038)$ and therefore undefined.

The $C V_{\mathrm{A}}$ for each of the characteristics follow the same pattern as the heritabilities (Table 1). Body size had a high $C V_{\mathrm{A}}$, while duration had a moderate value of $C V_{\mathrm{A}} ; C V_{\mathrm{A}}$ of the hiss frequency characteristics were lower than our estimate for duration.

\section{Correlations between male characteristics}

Table 2 presents phenotypic, genetic and environmental correlations between male weight, hiss duration, dominant frequency at the beginning of the hiss and dominant frequency at the end of the hiss. No correlations are presented for hiss rate because of the negative heritability estimate.

We found a significant phenotypic correlation between male weight and duration of the hiss $\left(r_{\mathrm{P}}=0.255, \quad N=118, \quad P=0.005\right)$. There was a moderate negative phenotypic correlation between male weight and dominant frequency measured at the beginning of the hiss $\left(r_{\mathrm{P}}=-0.182, \quad N=117\right.$, $P=0.048$ ) but this was not significant at a Bonferronicorrected level of significance $(P=0.025)$. The phenotypic correlation between the beginning and end measurements of dominant frequency was higher but not significant at a Bonferroni-corrected level of significance $\left(r_{\mathrm{P}}=0.204, N=112, P=0.030\right)$. No significant phenotypic correlations were found for duration and dominant frequency measured at the beginning of the hiss $\left(r_{\mathrm{P}}=-0.094, N=117, P=0.315\right)$ or duration and dominant frequency at the end of the hiss $\left(r_{\mathrm{P}}=-0.041, N=113, P=0.30\right)$.

We also found significant genetic correlations among the characteristics we examined (Table 2). We found a strong genetic correlation between male weight and duration of the agonistic hiss $\left(r_{\mathrm{G}}=0.593, \mathrm{SE}=0.121\right)$. We also found a strong negative genetic correlation between hiss duration and beginning dominant frequency $\left(r_{\mathrm{G}}=-0.602, \mathrm{SE}=0.305, P<0.05\right)$. No other pairs of variables had genetic correlations greater than their standard errors.

\section{Discussion}

In $G$. portentosa, males engage in agonistic interactions with other males. The maintenance of established dominance-subordinance associations is influenced by 
Table 1 Means, standard deviations and heritabilities of male size and characteristics of the agonistic hiss of Gramphadorhina portentosa

\begin{tabular}{lcccccc}
\hline Characteristics & Mean $\pm \mathrm{SD}$ & $\begin{array}{c}\text { Heritability } \\
\mathrm{h}^{2}\end{array}$ & $\begin{array}{c}\text { Standard } \\
\text { error }\end{array}$ & $\begin{array}{c}\text { Number of } \\
\text { families }(S)\end{array}$ & $\begin{array}{c}\text { Males per } \\
\text { family } \\
\left(n_{0}\right)^{\mathrm{b}}\end{array}$ & Evolvability \\
\hline Male Weight $(\mathrm{g})$ & $6.955 \pm 1.232$ & 0.926 & 0.148 & 56 & 3.571 & 44.969 \\
Hiss Duration $(\mathrm{s})$ & $0.591 \pm 0.136$ & 0.463 & 0.215 & 43 & 2.767 & 12.083 \\
$\begin{array}{l}\text { Hiss Rate } \\
\text { (number per minute) }\end{array}$ & $1.650 \pm 1.911$ & & & 56 & 2.744 & \\
$\begin{array}{l}\text { Dominant Frequency }(\mathrm{kHz}) \\
\quad \text { Beginning }\end{array}$ & $5.038 \pm 1.559$ & 0.219 & 0.214 & 43 & 2.721 & 7.682 \\
$\quad$ End & $5.094 \pm 1.431$ & 0.220 & 0.216 & 43 & 2.756 & 0.942 \\
\hline
\end{tabular}

Heritabilities were calculated from full-sib families.

${ }^{\text {a }}$ Negative genetic variance was found for hiss rate, therefore heritability and evolvability estimates are undefined.

${ }^{b}$ Corrected number of males (Becker, 1984).

Table 2 Genetic $\left(r_{\mathrm{G}}\right)$, phenotypic $\left(r_{\mathrm{P}}\right)$, and environmental $\left(r_{\mathrm{E}}\right)$ correlations among male size and characteristics of the agonistic hiss of Gramphadorhina portentosa

\begin{tabular}{|c|c|c|c|c|c|}
\hline Character pair & $\begin{array}{l}\text { Number of } \\
\text { families } S^{\text {a }}\end{array}$ & $\begin{array}{l}\text { Males per } \\
\text { family } n_{0}{ }^{\mathrm{b}}\end{array}$ & $\begin{array}{c}r_{\mathrm{G}} \\
(\mathrm{SE})\end{array}$ & $r_{\mathrm{P}}$ & $r_{\mathrm{E}}$ \\
\hline $\begin{array}{l}\text { Male Weight and } \\
\text { Agonistic Hiss Duration }\end{array}$ & 43 & 2.675 & $\begin{array}{c}0.593 \\
(0.121)\end{array}$ & 0.255 & -0.672 \\
\hline $\begin{array}{l}\text { Male Weight and } \\
\text { Beginning Dominant } \\
\text { Frequency }\end{array}$ & 43 & 2.652 & $\begin{array}{r}-0.228 \\
(0.256)\end{array}$ & -0.182 & 0.598 \\
\hline $\begin{array}{l}\text { Male Weight and } \\
\text { End Dominant Frequency }\end{array}$ & 41 & 2.683 & $\begin{array}{c}0.084 \\
(0.286)\end{array}$ & -0.059 & -0.406 \\
\hline $\begin{array}{l}\text { Agonistic Hiss Duration and } \\
\text { Beginning Dominant } \\
\text { Frequency }\end{array}$ & 43 & 2.652 & $\begin{array}{r}-0.602 \\
(0.305)\end{array}$ & -0.094 & 0.283 \\
\hline $\begin{array}{l}\text { Agonistic Hiss Duration and } \\
\text { End Dominant Frequency }\end{array}$ & 41 & 2.683 & $\begin{array}{l}-1.129 \\
(-0.128)\end{array}$ & -0.041 & 0.494 \\
\hline $\begin{array}{l}\text { Beginning Dominant Frequency } \\
\text { and End Dominant Frequency }\end{array}$ & 41 & 2.659 & $\begin{array}{c}0.172 \\
(0.107)\end{array}$ & 0.204 & 0.056 \\
\hline
\end{tabular}

${ }^{a}$ Families where we had data on both characteristics for at least two males per family.

${ }^{\mathrm{b}}$ Corrected number of males (Becker, 1984).

behaviour (namely aggression; Barth, 1968; Nelson \& Fraser, 1980; Breed et al., 1981; Clark \& Moore, 1994), acoustic signals (namely hissing; Nelson \& Fraser, 1980; Clark \& Moore, 1994, 1995b; Clark et al., 1995), and physical attributes of the male (namely size; this study). The outcome of male-male interactions may be important because dominant males are thought to limit the access of subordinates to receptive females (D. C. Clark, personal observation; Leibensperger et al., 1985). Therefore, variation among individuals in morphology, behaviour, and/or signals used during male-male competition has fitness consequences for the individuals involved.
We found that male size affected the outcome of agonistic interactions between pairs of $G$. portentosa males: a male that dominated in a pair was significantly larger than the male that was subordinate. Thus, the ability to recognize differences in size would allow males to avoid individuals likely to dominate in male-male competition, or larger males to dominate without continuous aggression. This species is nocturnal so the use of acoustic cues would be an effective way of communicating information about male size.

The need to discriminate among males based on physical attributes may have led to the evolution of agonistic hisses in $G$. portentosa. Fighting in $G$. 
portentosa can be costly as males may lose antennae or suffer other injuries. Losing an antenna may be disastrous for a species that also communicates using olfaction (Leibensperger et al., 1985). It has been suggested that males should settle costly contests by assessment if the cue used by males is a true indication of the opponent's likelihood of winning the encounter (Dawkins \& Krebs, 1978; Guilford \& Dawkins, 1991). In $G$. portentosa, there are significant phenotypic correlations between male weight and both the duration and dominant frequency of the agonistic hiss. However, the expression of these relationships is also strongly influenced by the environment: environmental influences that result in higher frequency hisses also produce shorter hisses. Therefore, the agonistic hiss produced by an individual may not be an accurate indicator of the male's present size. Because a small male could have a long hiss and vice versa, contests between males should not be settled on the basis of signalling alone. This could account for the use of aggression as well as agonistic hissing to maintain established dominance/subordinance associations in G. portentosa (Clark et al., 1995).

Although hiss characteristics are not a reliable cue for male-male interactions, hissing may be used by females to discriminate among potential mates. Males produce courtship hisses that do not differ from agonistic hisses in duration and dominant frequency (Clark \& Moore, 1995a). The genetic correlations between male size and hiss duration, and between hiss duration and frequency, are much stronger than the phenotypic correlations. Thus, the duration of the hiss could be used by females to assess the genotypic influence on size, whereas frequency allows assessment of environmental effects on duration and genetic quality of potential mates. Female G. portentosa prefer to mate with larger males (Clark \& Moore, 1995a) so the genetic correlation between male size and hiss characteristics may permit a 'good genes' mechanism of female choice. If females choose larger mates with lower frequency hisses then their sons are more likely to be larger and therefore, all other influences being equal, more likely to dominate in social interactions.

While sexual selection appears to be important, the evolution of a character also depends on the inheritance of the trait (Fisher, 1958). In G. portentosa, we found heritability estimates significantly different from zero for male weight $\left(h^{2}=0.926\right)$ and the duration of the hiss $\left(h^{2}=0.463\right)$. However, the use of heritability estimates to infer evolutionary patterns has been criticized (Houle, 1992). It has been suggested that evolvabilities should be calculated instead. Unlike previous studies (Houle, 1992; Messina, 1993) the pattern of heritability and evolvability was strikingly similar for the characters we measured. Therefore, our discussion of the evolutionary consequences of variation in agonistic hisses based on heritabilities holds for evolvabilities as well.

\section{Acknowledgements}

We thank Deidra Beshear, William Wallin and Ed Owen for care of the insects used in this study. Deidra Beshear, Butch Brodie, John Clark, Sandy DeBano, Dan Potter, William Wallin and an anonymous reviewer provided helpful discussions or comments on an earlier draft of this manuscript. We appreciate the financial support of this research by NSF Doctoral Dissertation Research Grant IBN-931 1109, NSF-KY EPSCoR Grant EHR-9108764 for summer research funds, Sigma Xi Grant-in-Aid of Research (to D.C.C.) and NSF Grants BSR-902 2012 and DEB-9107078, University of Kentucky Research Committee Grant, State and Federal Hatch funds, and funds provided by the Vice Chancellor for Research and Graduate Studies (to AJM). KAES publication number 94-7231.

\section{References}

ASPI, J. AND HOIKKALA, A. 1993. Laboratory and natural heritabilities of male courtship song characters in Drosophila montana and D. littoralis. Heredity, 70, 400-406.

BARTH, R. H. 1968. The mating behavior of Gromphadorhina portentosa (Schaum) (Blattaria, Blaberoidae, Blaberidae, Oxyhaloniae): an anomalous pattern for a cockroach. Psyche, 75, 124-131.

BECKER, W. A. 1984. Manual of Quantitative Genetics, 4th edn. Academic Enterprises, Washington.

BOAKE, C. R. B. 1989. Correlations between courtship success, aggressive success, and body size in a picture-winged fly, Drosophilia silvestris. Ethology, 80, 318-329.

BOAKE, C. R. B. 1991. Coevolution of senders and receivers of sexual signals: genetic coupling and genetic correlations. Trends Ecol. Evol., 6, 225-227.

BREED, M. D., MEANEY, C., DEUTH, D. AND BELL, W. J. 1981. Agonistic interactions of two cockroach species, Gromphadorhina portentosa and Supella longipalpa (Orthoptera (Dictyoptera): Blaberidae, Blattelidae). $J$. Kans. Entomol. Soc., 54, 197-208.

CLARK, D. C. AND MOORE, A. J. 1994. Social interactions and aggression among male Madagascar hissing cockroaches (Gromphadorhina portentosa) in groups (Dictyoptera: Blaberidae). J. Insect Behav., 7, 199-215.

CLARK, D. C. AND MOORE, A. J. 1995a. Social communication in the Madagascar hissing cockroach: features of male courtship hisses and a comparison of courtship and agonistic hisses. Behaviour, in press.

CLARK, D. C. AND MOORE, A. J. 1995b. Variation and repeatability of male agonistic hiss characteristics and their relationship to social rank in Gromphadorhina portentosa. Anim. Behav., in press.

(C) The Genetical Society of Great Britain, Heredity, 75, 198-205. 
CLARK, D. C., BESHEAR, D. D. AND MOORE, A. J. 1995. The role of familiarity in structuring male-male social interactions in the cockroach Gromphadorhina portentosa (Dictyoptera: Blaberidae). Ann. Entomol. Soc. Am., in press.

DARWIN, C. R. 1859. On the Origin of Species by Means of Natural Selection. John Murray, London.

DAVIES, N. B. AND HALLIDAY, T. R. 1978. Deep croaks and fighting assessment in toads, Bufo bufo. Nature, 274, 683-685.

DAWKINS, R. AND KREBS, J. R. 1978. A nimal signals: information or manipulation? In Krebs, J. R. and Davies, N. B. (eds) Behavioral Ecology: An Evolutionary Approach, 1st edn, pp. 282-309. Blackwell Scientific Publications, Oxford.

DE WINTER, A. J. 1992. The genetic basis and evolution of acoustic mate recognition signals in Ribautodelphax planthopper (Homoptera, Delphacidae). I. The female call. $J$. Evol. Biol., 5, 249-265.

DEWSBURY, D. A. 1990. Fathers and sons: genetic factors and social dominance in deer mice, Peromyscus maniculatus. Anim. Behav., 39, 284-289.

EBERhard, w. G. 1979. The function of horns in Podischnus agenor (Dynastinae) and other beetles. In: Blum, M. S. and Blum, N. A. (eds) Sexual Selection and Reproductive Competition in Insects, pp. 231-258. Academic Press, New York.

FABER, D. B. AND BAYLIS, J. R. 1993. Effects of body size on agonistic encounters between male jumping spiders (Araneae: Salticidae). Anim. Behav., 45, 289-299.

FALCONER, D. S. 1989. Introduction to Quantitative Genetics, 3rd edn. Longman Press, London.

FISHER, R. A. 1958. The Genetical Theory of Natural Selection, 2nd edn. Dover Publications, New York.

GUILFORD, T. AND DAWKINS, M. s. 1991. Receiver psychology and the evolution of animal signals. Anim. Behav., 42, 1-14.

HEDRICK, A. V. 1988. Female choice and the heritability of attractive male traits: an empirical study. Am. Nat., 132, 267-276.

HOFFMAN, A. A. 1988. Heritable variation for territorial success in two Drosophila melanogaster populations. Anim. Behav., 36, 1180-1189.

HOULE, D. 1992. Comparing evolvability and variability of quantitative traits. Genetics, 130, 195-204.

HUNTingford, F. AND TURNer, A. 1987. Animal Conflict. Chapman and Hall, New York.

LANDE, R. 1979. Quantitative genetic analysis of multivariate evolution, applied to brain:body size allometry. Evolution, 33, 402-416.

LANDE, R. 1980. Sexual dimorphism, sexual selection, and adaptation in polygenic characters. Evolution, 34, 292-305.
LANDE, R. 1982. A quantitative genetic theory of life history evolution. Ecology, 63, 607-615.

LEIBENSPERGER, L. B., TRANIELLO, J. F. A. AND FRASER, J. M. 1985. Olfactory cues used by female Gromphadorhina portentosa (Dictyoptera: Blaberidae) during mate choice. Ann. Entomol. Soc. Am., 78, 629-634.

manty, B. F. J. 1991. Randomization and Monte Carlo Methods in Biology. Chapman and Hall, London.

MAYNARD SMITH, J. 1982. Evolution and the Theory of Games. Cambridge University Press, Cambridge.

MEssinA, F. J. 1993. Heritability and 'evolvability' of fitness components in Callosobruchus maculatus. Heredity, 71, 623-629.

MOORE, A. J. 1990. The inheritance of social dominance, mating behaviour and attractiveness to mates in male Nauphoeta cinerea. Anim. Behav., 39, 388-397.

MOUSSEAU, T. A. AND ROFF, D. A. 1987. Natural selection and the heritability of fitness components. Heredity, 59, 181-197.

NELSON, M. C. AND FRASER, J. 1980. Sound production in the cockroach Gromphadorhina portentosa: evidence for communication by hissing. Behav. Ecol. Sociobiol., 6, 305-314.

PARKER, G. A. 1974. Assessment strategy and the evolution of fighting behaviour. J. theor, Biol., 47, 223-243.

POTTER, D. A., WRENSCH, D. L. AND JOHNSTON, D. E. 1976. Aggression and mating success in male spider mites. Science, 193, 160-161.

RICE, W. R. 1989. Analyzing tables of statistical tests. Evolution, 43, 223-225.

RIECHERT, S. E. AND MAYNARD SMITH, J. 1989. Genetic analysis of two behavioural traits linked in individual fitness in the desert spider Agelenopsis aperta. Anim. Behav., 37, 624-637.

ROBERTSON, J. G. 1986. Male territoriality, fighting and assessment of fighting ability in the Australian frog, Uperoleia rugosa. Anim. Behav., 34, 763-772.

ROFF, D. A. AND MOUSSEAU, T. A. 1987. Quantitative genetics and fitness: lessons learned from Drosophila. Heredity, 58, 103-118.

THORNHILl, R. 1983. Fighting and assessment in Harpobittacus scorpionflies. Evolution, 38, 204-214.

WAGNER, w. E., Jr. 1989. Fighting, assessment, and frequency alteration in Blanchard's cricket frog. Behav. Ecol. Sociobiol., 25, 429-436.

WEBB, K. L. AND ROFF, D. A. 1992. The quantitative genetics of sound production in Gryllus firmus. Anim. Behav., 44, 823-832.

WILKINSON, L. 1990. sYSTAT, The System for Statistics. SYSTAT, IL, USA. 